\title{
A IMPORTÂNCIA DA REFLEXÃO ARENDTIANA ACERCA DA CRISE DA AUTORIDADE PARA UMA POSSÍVEL INTERPRETAÇÃO POLÍTICA DA SENTENÇA NIETZSCHEANA "DEUS ESTÁ MORTO"
}

\author{
The Importance of Arendt's Reflection about the Crisis of the Authority for a Possible Political \\ Interpretation of the Nietzsche's Sentence "God is Dead"
}

\begin{abstract}
Resumo: O esforço consiste em demonstrar a importância da reflexão de Arendt acerca da crise da autoridade para uma possível interpretação política da sentença nietzscheana "Deus está morto". A pensadora expõe o seu conceito de autoridade na obra Entre o passado e o futuro, no capítulo "Que é autoridade?", distinguindo-o de persuasão e violência. As duas últimas, respectivamente, necessitam de argumento e força para surtirem algum efeito no mundo, enquanto a autoridade recorre tão-somente à sua própria tradição. Entretanto, segundo o diagnóstico arendtiano, a autoridade entra em crise no mundo moderno, pois se dissolve a tradição na qual ela se ancorava. Com base nisso, o artigo apresenta a crítica de Nietzsche à tradição, inferindo que sua sentença "Deus está morto" consiste no fim da autoridade analisada por Arendt. De acordo com o filósofo, será pensado como, após a "morte de Deus", o homem moderno encontra para este um substituto. Trata-se do Estado que, sem uma tradição para legitimar sua autoridade, de autoritário passa a ser totalitário.
\end{abstract}

Palavras-chave: Autoridade, Estado, Crise, Morte de Deus.

\begin{abstract}
The work consists in demonstrate the importance of Arendt's reflection on the crisis of authority for a possible political interpretation of the nietzschean sentence "God is dead". The thinker exposes her concept of authority in the work "Between the past and the future", in the chapter "What is authority?", distinguishing it from persuasion and violence. These, respectively, need argument and force to be effective in the world, while authority resorted to its own tradition. However, according to the Arendt's diagnosis, authority enters into crisis in the modern world, since the tradition in which it has anchored dissolves. In this way, the work presents Nietzsche's critique of tradition, inferring that the sentence "God is dead" is the end of the authority analyzed by Arendt. Acoording to the philosopher, it will be thought how, after the "death of God", modern man finds for him a substitute. It is the state that, without a tradition to legitimize its authority, of authoritarian becomes totalitarian.
\end{abstract}

Keywords: Authority, State, Crisis, Death of God.

\footnotetext{
* Mestre em Filosofia pela UFPI. E-mail: j.roberto-10@ @otmail.com.
}

\begin{tabular}{|c|c|l|l|c|c|}
\hline intuitio & $\begin{array}{c}\text { ISSN } \\
1983-4012\end{array}$ & Porto Alegre & Vol.11- $\mathrm{N}^{\mathrm{o} .2}$ & $\begin{array}{c}\text { Dezembro } \\
2018\end{array}$ & p.101-122 \\
\hline
\end{tabular}


A Importância da Reflexão Arendtiana Acerca da Crise da Autoridade para uma Possível Interpretação Política da Sentença Nietzcheana "Deus Está Morto"

\section{Introdução}

Para Arendt (2005), a autoridade se encontra tão em crise que já não é mais cabível perguntar pelo o que ela é, sendo mais contextual perguntar pelo o que ela foi. O mundo moderno não tem experiência adequada do que seja autoridade, por isso a compreensão desta é comumente equivocada, como quando é confundida com violência. De fato, a autoridade não é violência nem persuasão, pois lhe é crucial não recorrer a nada além de si para ser obedecida. Por outro lado, diz a filósofa, violência e persuasão não são autoridades, pois necessitam, sucessivamente, de força e argumento para surtirem algum efeito no mundo.

Necessitando apenas de si mesma, a autoridade está baseada na tradição e na memória de um povo; a forma de governo a ela relacionada é o autoritarismo, que, em decorrência da confusão moderna entre autoridade e violência, tem sido confundido com ditadura, tirania e, mais absurdamente, totalitarismo. Com efeito, nada mais distinto do autoritarismo que o totalitarismo, pois este teve como campo fértil para seu surgimento o fim da autoridade, fim este que lhe deu caminho para exercer poder total e violento sobre a vida.

Longe de ser um poder total, o autoritarismo não suprime a liberdade, apenas a restringe hierarquicamente, conservando a cidadania. Para Arendt (2005), foram os romanos que melhor compreenderam-no. Era-lhes comum a ideia de que a autoridade maior estava no caráter de fundação da cidade, cuja tradição enviava o peso dos feitos do passado para o presente, presente que devia conservá-lo para o futuro, expandindo-se a todo lugar aonde chegasse a sua memória. Nesse contexto, a hierarquia se estabelecia cronologicamente entre os mais distantes e os mais próximos do passado glorioso, de modo que quanto mais próximo da fundação da cidade e de sua memória, mais autoridade, cuja tradição não precisava nem de persuasão nem de violência para ser transmitida e assimilada.

Contudo, a pensadora adverte que, entre os gregos, não havia conhecimento desse conceito de autoridade. A política grega se baseava na persuasão, ou seja, não havia autoridade no sentido romano, e tudo era preciso ser levado à praça pública para ser legitimado por meio do argumento. Fora isso, o grego tinha em mente o elemento da violência, que era próprio aos tiranos, cuja palavra era imposta pela força, sem persuasão.

Ora, é justamente isto que precisa ser assimilado, caso se queira compreender a gênese do conceito Ocidental de autoridade. Visto a crise da democracia Grega, Platão tentou criar um

\begin{tabular}{|c|c|c|c|c|c|}
\hline intuitio & $\begin{array}{c}\text { ISSN } \\
1983-4012\end{array}$ & Porto Alegre & Vol.11- N $^{\circ} .2$ & $\begin{array}{c}\text { Dezembro } \\
2018\end{array}$ & p.101-122 \\
\hline
\end{tabular}


A Importância da Reflexão Arendtiana Acerca da Crise da Autoridade para uma Possível Interpretação Política da Sentença Nietzcheana "Deus Está Morto"

conceito de autoridade para o mundo grego, por meio do qual fosse possível obedecer sem violência e persuasão. No contexto filosófico, como afirma Arendt, o pensador ateniense viu na ideia de Verdade (o Bem, o Belo e Justo) essa autoridade incondicional. Contudo ela carecia de tradição, então como se legitimaria na política? Este foi um dos principais problemas de Platão, sobretudo porque a Verdade como autoridade só era assimilada sem violência e persuasão por filósofos, enquanto a multidão lhe era indiferente. Para resolver isso, conta Arendt (2005), Platão teria inventado a teologia, que, muito diferente do seu significado moderno, era uma área da "Ciência Política", que estabelecia os mecanismos pelos quais poucos podiam governar muitos. No cerne da teologia estava a ideia de Deus, que servia como artifício soberano para punir os injustos e beneficiar os justos em uma vida futura. Desse modo, Platão teria sido o precursor do mito do céu e do inferno, que, segundo a interpretação de Arendt, foram adaptações e distorções intencionais da teoria da imortalidade da alma para fins políticos, uma vez que ele estava certo de que o mito conseguiria envolver mais facilmente, em vez do exercício da razão, a multidão aos seus propósitos.

Sendo assim, surge Deus como um artifício político da teologia de Platão para ser o juiz supremo do mito de punição e recompensa, presente no décimo livro d'A República, com o nome de mito de Er. Consequentemente, ao adotar a literatura platônica em seu meio cultural, o mundo romano, já decadente, enviou para a posteridade esses mitos por meio do cristianismo, que por sua vez se aproveitou da cultura platônica para se efetivar naquele mundo. Assim, o conceito de autoridade que o ocidente herdou, que se encontra em crise na modernidade, tem origem platônico-cristã.

Tomando isso como fio condutor, será pensado em que medida tais reflexões contribuem para uma interpretação política da sentença nietzscheana "Deus está morto", já que o filósofo que a anunciou também tinha realizado um diagnóstico preciso sobre a crise da autoridade platônicocristã. Em Assim falou Zaratustra, Nietzsche afirma que, após a morte de Deus, o homem criou para si um "novo ídolo", a fim de substituir a velha autoridade divina. Tal novo ídolo, que também haveria de fracassar, seria o Estado, cujo valor faz transparecer o caráter político da morte de Deus. Ora, percebe-se aqui uma abordagem que se distingue da realizada pela maioria dos estudiosos de Nietsche, para os quais o grande novo ídolo a substituir Deus seria a ciência moderna. Este artigo, contudo, não quer dizer que tais abordagens estão equivocadas, mas complementá-las. Procura-se demonstrar, com base na reflexão de Arendt sobre a crise da

\begin{tabular}{|c|c|l|l|c|c|}
\hline intuitio & $\begin{array}{c}\text { ISSN } \\
1983-4012\end{array}$ & Porto Alegre & Vol.11- No.2 & $\begin{array}{c}\text { Dezembro } \\
2018\end{array}$ & p.101-122 \\
\hline
\end{tabular}


A Importância da Reflexão Arendtiana Acerca da Crise da Autoridade para uma Possível Interpretação Política da Sentença Nietzcheana "Deus Está Morto"

autoridade, que para Nietzsche é o Estado, tal como o é a ciência no âmbito do conhecimento, o grande ídolo a substituir Deus no âmbito da política, ideia esta que pode ser encontrada no aforismo 472 de Humano demasiado humano. Contudo, como está expresso neste mesmo aforismo, o Estado moderno é uma tentativa de substituir Deus fadada ao fracasso, pois, sendo artificial, falta-lhe autoridade e tradição para subjugar as liberdades individuais. Para Sloterdijk (1999), intérprete contemporâneo de Nietzsche, no livro No mesmo barco: ensaio sobre a hiperpolítica, a "morte de Deus" representa no âmbito político a impossibilidade do sentimento de coopertencimento de um grande número de pessoas em relação a um Grande (Estado), algo que conduz a uma acentuada fragmentação, a qual marca o fim da política clássica e o início do pós-moderno.

Sendo assim, o corpo do presente artigo se divide em três tópicos. O primeiro, A crise da autoridade segundo Hannah Arendt, tem o seguinte problema: Como o Ocidente, passando pela experiência dos movimentos totalitários e pela perda da tradição, não conhece mais a natureza da autoridade e a confunde com violência? O segundo, A origem romana da autoridade e sua versão platônica: Como no mundo romano a autoridade dispensa a violência e a persuasão para recorrer apenas à sua própria tradição? Como Platão tenta desenvolver um modelo semelhante de autoridade com sua teologia política, em cujo cerne se encontra a ideia de Deus legislador? Como esse modelo foi assimilado pelo cristianismo e entrou em crise na modernidade? O terceiro e último tópico, O significado político da sentença nietzscheana "Deus está morto": Em que medida a reflexão de Arendt sobre a crise da autoridade no Ocidente, de origem platônico-cristã, pode ajudar a compreender politicamente a sentença nietzscheana "Deus está morto"? A partir de Nietzsche, pode-se inferir que o Estado moderno é considerado o substituto de Deus após sua morte? Seria a violência o principal meio do Estado destituído de tradição que quer exercer "autoridade" absoluta?

\section{A Crise da Autoridade segundo Hannah Arendt}

Em Entre o passado e o futuro, Arendt faz a seguinte questão: “Que é autoridade?". Segundo ela, trata-se de uma questão que precisa ser reformulada, uma vez que o homem moderno perdeu de vista a experiência da autoridade, sendo mais cabível esta pergunta: o que foi a autoridade? De início, Arendt adverte que não se trata de uma autoridade em geral, "mas antes

\begin{tabular}{|c|c|l|l|c|c|}
\hline intuitio & $\begin{array}{c}\text { ISSN } \\
1983-4012\end{array}$ & Porto Alegre & Vol.11- No.2 & $\begin{array}{c}\text { Dezembro } \\
2018\end{array}$ & p.101-122 \\
\hline
\end{tabular}


A Importância da Reflexão Arendtiana Acerca da Crise da Autoridade para uma Possível Interpretação Política da Sentença Nietzcheana "Deus Está Morto"

uma forma bem específica, que fora válida em todo o mundo ocidental durante longo período de tempo"1. A pensadora, portanto, busca um conceito historicamente situado, cujo sentido se encontra em crise na modernidade. Mas, não se trata de uma crise qualquer: é uma crise essencialmente política, pois a autoridade até então tinha sido suporte e fundamento para o pensamento político ocidental.

Para Arendt, na prática, essa crise encontrou sua maior manifestação no totalitarismo: “o desenvolvimento de uma nova forma totalitária de governo, tiveram lugar contra o pano de fundo de uma quebra mais ou menos geral e mais ou menos dramática de todas as autoridades tradicionais" ". Tal crise começa na esfera política, mas se espalha em áreas pré-políticas, como a educação e a criação dos filhos, onde até então a autoridade era inalienável e cujo caráter servia de modelo para governos autoritários. Disso se conclui que: "o fato de mesmo essa autoridade pré-política, que governava as relações entre adultos e crianças e entre mestres e alunos, não ser mais segura significa que todas as antigas e reputadas metáforas e modelos de relações autoritárias perderam a plausibilidade" ${ }^{\text {.3 }}$ Por isso, diz Arendt, é importante não confundir autoritarismo com totalitarismo: justamente lá onde está a impossibilidade do autoritarismo é que se encontra o campo fértil para o totalitarismo. Pois o totalitarismo, como poder total, aproveitase da crise da autoridade em diversas áreas da vida para exercer sobre ela o seu domínio.

Contudo, mesmo que o significado de autoridade tenha perdido o seu sentido originário, trata-se ainda de uma palavra muito presente na linguagem cotidiana. Por isso, embora muito se fale de autoridade, muito deste falar está envolvido em confusões conceituais, conscientes ou não. O que Arendt destaca é que, pelo fato de essa palavra estar associada à obediência e ainda persistir na linguagem mesmo com a perda de seu sentido originário, é que muitos a confundem com violência. Para compreender o significado de autoridade é preciso levar isso em consideração, pois a obediência que ela demanda não recorre a nada além de si mesma, de modo que tanto a violência (força) como a persuasão (convencimento) já a levariam ao fracasso:

Contudo, a autoridade exclui a utilização de meios externos de coerção; onde a força é usada, a autoridade em si mesmo fracassou. A autoridade, por outro lado, é incompatível

\footnotetext{
${ }^{1}$ ARENDT, H. "Que é autoridade?". In: ARENDT, H. Entre o passado e o futuro. Tradução de Mauro W. Barbosa. Ed. São Paulo: Perspectiva, 2005, p. 129.

2 ARENDT, H. “Que é autoridade?”. In: ARENDT, H. Entre o passado e o futuro. Tradução de Mauro W. Barbosa. Ed. São Paulo: Perspectiva, 2005, p. 128.

${ }^{3}$ ARENDT, H. "Que é autoridade?". In: ARENDT, H. Entre o passado e o futuro. Tradução de Mauro W. Barbosa. Ed. São Paulo: Perspectiva, 2005, p. 128.
}

\begin{tabular}{|c|c|c|c|c|c|}
\hline intuitio & $\begin{array}{c}\text { ISSN } \\
1983-4012\end{array}$ & Porto Alegre & Vol.11- No.2 & $\begin{array}{c}\text { Dezembro } \\
2018\end{array}$ & p.101-122 \\
\hline
\end{tabular}


A Importância da Reflexão Arendtiana Acerca da Crise da Autoridade para uma Possível Interpretação Política da Sentença Nietzcheana "Deus Está Morto"

com a persuasão, a qual pressupõe igualdade e opera mediante um processo de argumentação. Onde se utilizam argumentos, a autoridade é colocada em suspenso. Contra a ordem igualitária da persuasão ergue-se a ordem autoritária, que é sempre hierárquica. ${ }^{4}$

Arendt diz a um só tempo o que não é e o que é autoridade. Não é violência nem persuasão, pois estes dois meios de exigir obediência recorrem a fatores alheios à sua natureza, que são a força e o argumento. Por outro lado, ela é autossuficiente, e disto vem a sua reivindicação por obediência; e também se constitui de forma hierárquica, cuja legitimidade é reconhecida por todos que encontram nela o seu lugar.

Sendo assim, é preciso penetrar no que seja a autoridade, compreendendo o que perpassa esta sua autossuficiência. Para Arendt, historicamente o que fundamenta a autoridade é a tradição. Aqui, a autora faz uma distinção basilar, entre tradição e passado: “com a perda da tradição, perdemos o fio que nos guiou com segurança através dos vastos domínios do passado; esse fio, porém, foi também a cadeia que aguilhou cada sucessiva geração a um aspecto predeterminado do passado" ". Assim, enquanto o passado é a sucessão de eventos que foram ficando para trás, a tradição é o que possibilita aos seres humanos se ancorarem em tais eventos, onde a memória exerce um papel fundamental enquanto dimensão da profundidade humana. Em face disso, a crise da autoridade é ao mesmo tempo a crise da tradição e da memória, as quais garantiam a permanência e a segurança de um mundo em comum.

No Ocidente, nenhuma instituição esteve mais ancorada na tradição que a religiosa, de modo que a crise da autoridade explica o motivo pelo qual a influência da religião foi decaindo cada vez mais diante do mundo secularizado. Desde então, segundo Arendt, iniciou-se a disputa entre conservadores e liberais. Os primeiros sempre indicando a necessidade de conservação da tradição, salvaguardando-a da decadência; e os segundos, apontando a superação da tradição como um progresso:

O liberalismo e o conservadorismo nasceram nesse clima de opinião pública violentamente oscilante, e ligam-se um ao outro, não apenas porque cada um deles perderia um ao outro, não apenas porque cada um deles perderia sua própria essência sem a presença do oponente no campo da teoria e da ideologia, mas também por se

\footnotetext{
${ }^{4}$ ARENDT, H. “Que é autoridade?”. In: ARENDT, H. Entre o passado e o futuro. Tradução de Mauro W. Barbosa. Ed. São Paulo: Perspectiva, 2005, p. 129.

${ }^{5}$ ARENDT, H. “Que é autoridade?". In: ARENDT, H. Entre o passado e o futuro. Tradução de Mauro W. Barbosa. Ed. São Paulo: Perspectiva, 2005, p. 130.
}

\begin{tabular}{|c|c|c|c|c|c|}
\hline intuitio & $\begin{array}{c}\text { ISSN } \\
1983-4012\end{array}$ & Porto Alegre & Vol.11 $-\mathrm{N}^{\circ} .2$ & $\begin{array}{c}\text { Dezembro } \\
2018\end{array}$ & p.101-122 \\
\hline
\end{tabular}


A Importância da Reflexão Arendtiana Acerca da Crise da Autoridade para uma Possível Interpretação Política da Sentença Nietzcheana "Deus Está Morto"

preocuparem ambos fundamentalmente com a restauração, seja da liberdade, da autoridade ou do relacionamento entre ambas, à sua posição tradicional. ${ }^{6}$

Para Arendt, de alguma forma, a confusão do conceito de autoridade com violência teve como uma das principais causas o pensamento liberal. Tendo a liberdade como fundamento, esse pensamento tinha colocado em um único conjunto todos aqueles que obstruíam o rumo progressivo da liberdade, como se não houvesse entre eles nenhuma diferença essencial, mas apenas de grau de obstrução do progresso. Para o liberal, tudo o que corrompe a liberdade tirania, ditadura ou totalitarismo - compartilha do mesmo atraso, e o autoritarismo enquanto limitador da liberdade estaria no mesmo conjunto:

Isso faz com que passem por alto a diferença de princípio entre a restrição da liberdade em regimes autoritários, a abolição da liberdade política em tiranias e ditaduras, e a total eliminação da própria espontaneidade, isto é, da mais geral e elementar manifestação da liberdade humana a qual somente visam os regimes totalitários, por intermédio de seus diversos métodos de condicionamento. ${ }^{7}$

Diz Arendt que essa pressa no julgamento resultou na má compreensão do autoritarismo, que se distingue das outros regimes mencionados justamente no seu trato com a liberdade política. Diferente dos demais governos mencionados, o autoritarismo não suprime a liberdade (se o fizesse, seria tirania), ele apenas a restringe, permanecendo aos cidadãos os seus direitos civis. Justamente por não abolir a liberdade é que o autoritarismo não pode estar fundamentado na violência. No seu interior, a obediência à autoridade se apresenta como uma ação civil que conserva a liberdade na medida em que a restringe. Diferente da tirania, o governo autoritário não restringe a liberdade de maneira arbitrária, pois sua ação é sempre limitada por leis, cuja legitimidade se encontra na autoridade, cujas fontes estão na tradição:

A origem da autoridade no governo autoritário é sempre uma força externa e superior a seu próprio poder; é sempre dessa fonte, dessa força externa que transcende a esfera política, que as autoridades derivam sua "autoridade" - isto é, sua legitimidade - e em relação à qual seu poder pode ser confirmado. ${ }^{8}$

\footnotetext{
${ }^{6}$ ARENDT, H. “Que é autoridade?”. In: ARENDT, H. Entre o passado e o futuro. Tradução de Mauro W. Barbosa. Ed. São Paulo: Perspectiva, 2005, p. 138.

${ }^{7}$ ARENDT, H. “Que é autoridade?". In: ARENDT, H. Entre o passado e o futuro. Tradução de Mauro W. Barbosa. Ed. São Paulo: Perspectiva, 2005, p. 133.

${ }^{8}$ ARENDT, H. “Que é autoridade?”. In: ARENDT, H. Entre o passado e o futuro. Tradução de Mauro W. Barbosa.
}

\begin{tabular}{|c|c|c|c|c|c|}
\hline intuitio & $\begin{array}{c}\text { ISSN } \\
1983-4012\end{array}$ & Porto Alegre & Vol.11 $-\mathrm{N}^{\circ} .2$ & $\begin{array}{c}\text { Dezembro } \\
2018\end{array}$ & p.101-122 \\
\hline
\end{tabular}


A Importância da Reflexão Arendtiana Acerca da Crise da Autoridade para uma Possível Interpretação Política da Sentença Nietzcheana "Deus Está Morto"

Assim, somente da tradição as autoridades políticas retiram a sua autoridade em um governo autoritário. E é dessa tradição que vem a necessidade de obediência ao governo. Não há aí nenhuma necessidade de violência. Contudo, como o homem moderno perdeu de vista o valor da autoridade, então ele não consegue compreender a obediência senão atrelada à violência. Só que, ao fazer isso, ele não está mais falando de autoridade, embora use esta palavra para se expressar. Em verdade, trata-se de ditadura ou totalitarismo, que fazem obedecer com violência e não com o peso da memória e da tradição. "Todos aqueles que chamam as modernas ditaduras de "autoritárias", ou confundem o totalitarismo com uma estrutura autoritária, equacionam implicitamente violência com autoridade"9. Ora, esse equacionamento é um equívoco, pois nem tudo que exige obediência é violento, como é o caso da autoridade. Contudo, é importante perguntar: Qual a sua origem? Quais foram as suas transformações? Que tipo de autoridade o Ocidente herdou para que se encontre em crise na modernidade? A seguir, será visto como Arendt pensa a origem da noção de autoridade no mundo romano, bem como seu desdobramento histórico por meio do platonismo.

\section{A Origem Romana da Autoridade e sua Versão Platônica}

Tradicionalmente, o sentido originário de autoridade é de origem romana, tanto a palavra como o conceito. Neste contexto, a autoridade suprema é o caráter sagrado da fundação da cidade. O papel da religião era crucial: religar (re-ligare) o romano ao passado glorioso da fundação. Aqueles que obtinham essa tradição, os anciãos, o Senado ou os patres, tinham de transmiti-la às gerações futuras. Contavam os feitos dos fundadores, chamados maiores ${ }^{10}$.

Essa autoridade, porém, não se transmitia pela força: “o caráter autoritário do 'acréscimo’ dos anciões repousa em sua natureza de mero conselho, prescindindo, seja da forma de ordem, seja de coerção externa, para fazer-se escutado" "11. Para a obediência bastava o peso do passado e os seus exemplos. Não por acaso, diz Arendt, o valor do ancião não estava simplesmente por ser

Ed. São Paulo: Perspectiva, 2005, p. 134.

${ }^{9}$ ARENDT, H. “Que é autoridade?". In: ARENDT, H. Entre o passado e o futuro. Tradução de Mauro W. Barbosa. Ed. São Paulo: Perspectiva, 2005, p. 141.

${ }^{10}$ ARENDT, H. "Que é autoridade?". In: ARENDT, H. Entre o passado e o futuro. Tradução de Mauro W. Barbosa. Ed. São Paulo: Perspectiva, 2005, p. 163-164.

${ }^{11}$ ARENDT, H. "Que é autoridade?". In: ARENDT, H. Entre o passado e o futuro. Tradução de Mauro W. Barbosa. Ed. São Paulo: Perspectiva, 2005, p. 165.

\begin{tabular}{|c|c|c|c|c|c|}
\hline intuitio & $\begin{array}{c}\text { ISSN } \\
1983-4012\end{array}$ & Porto Alegre & Vol.11 $-\mathrm{N}^{\circ} .2$ & $\begin{array}{c}\text { Dezembro } \\
2018\end{array}$ & p.101-122 \\
\hline
\end{tabular}


A Importância da Reflexão Arendtiana Acerca da Crise da Autoridade para uma Possível Interpretação Política da Sentença Nietzcheana "Deus Está Morto"

o mais velho, mas porque ele veio ao mundo muito mais próximo daqueles antepassados maiores. Logo, quanto mais próximo temporalmente dos fundares, mais memória, mais autoridade, mais tradição.

Essa relação dos romanos com a autoridade era tão forte que era levada para onde quer que eles fossem. É por isso que não instalaram colônias, mais alargaram a fundação original por um vasto território, até que Roma se tornasse Império. Com relação a isso, "a palavra autoritas é derivada do verbo augere, "aumentar", e aquilo que a autoridade ou os de posse dela constantemente aumentam é a fundação"12. De fato, isso demonstra o enraizamento profundo do romano (muito mais que os gregos) com sua tradição, que não se desenraiza, mas expande o seu território para "sentir-se sempre em casa".

Quanto aos gregos, não se pode dizer que conheciam essa autoridade e nem essa expansão territorial: "nem a língua grega nem as várias experiências políticas da história grega mostram qualquer conhecimento da autoridade e do tipo de governo que ela implica"13. E isso por uma razão bem simples: a política grega e sua democracia tinham por base a persuasão. Viu-se que a autoridade não é só distinta da violência, mas também da persuasão, pois esta recorre a argumentos, meios distintos de si, enquanto que a autoridade é autossuficiente. Para os gregos, a palavra era o mais importante; contudo, esta não se tratava de uma autoridade no sentido romano, pois era sempre colocada em questão por outras palavras no espaço público; caso contrário, o cidadão estaria sendo subjugado pela arbitrariedade violenta de um tirano, que não admitia questionamento.

Apesar disso, com a crise da democracia, com o fantasma da tirania, Platão se encontrou na necessidade de estabelecer um modelo de autoridade para o mundo grego em sua República, como bem aponta Arendt. Como o grego não tinha experiência de autoridade, então a única relação de obediência que ele conhecia era a do ambiente doméstico, entre senhor e escravo, fundada na coerção. Então, se Platão quisesse fundar uma autoridade em solo grego, não lhe haveria outro modelo senão o doméstico; contudo, teria que suavizar essa relação através de um princípio que não necessitasse nem de violência nem de persuasão. Para o filósofo, esse princípio seria a Verdade, que num contexto meramente filosófico e ainda não político tem a ver com o

\footnotetext{
${ }^{12}$ ARENDT, H. "Que é autoridade?". In: ARENDT, H. Entre o passado e o futuro. Tradução de Mauro W. Barbosa. Ed. São Paulo: Perspectiva, 2005, p. 163-164.

${ }^{13}$ ARENDT, H. "Que é autoridade?". In: ARENDT, H. Entre o passado e o futuro. Tradução de Mauro W. Barbosa. Ed. São Paulo: Perspectiva, 2005, p. 142.
}

\begin{tabular}{|c|c|c|c|c|c|}
\hline intuitio & $\begin{array}{c}\text { ISSN } \\
1983-4012\end{array}$ & Porto Alegre & Vol.11 $-\mathrm{N}^{\circ} .2$ & $\begin{array}{c}\text { Dezembro } \\
2018\end{array}$ & p.101-122 \\
\hline
\end{tabular}


A Importância da Reflexão Arendtiana Acerca da Crise da Autoridade para uma Possível Interpretação Política da Sentença Nietzcheana "Deus Está Morto"

belo, com o que brilha por si mesmo e cuja claridade é contemplada pela razão: "a função original das ideias não era governar ou determinar de alguma forma outra maneira o caos dos assuntos humanos, mas sim, com ‘irradiante brilho', iluminar sua escuridão"14. Assim, Platão observa na ideia de belo uma autoridade útil para a política, ideia que agora não deve ser apenas iluminadora, mas um bem capaz de se transformar em um conjunto de regras para a cidade. Aqui, o belo, estritamente filosófico, transforma-se enfim na ideia de bem, de caráter político. Em outras palavras: a verdade do filósofo pretende ser a verdade da cidade, sua autoridade e seu Bem. Tal como a autoridade romana, essa verdade não necessitaria persuadir e nem violentar para ser o que é: "bem no início de sua procura deve ter descoberto que a verdade, isto é, as verdades que chamamos de auto-evidentes, compelem a mente, e que essa coerção, embora não necessite de nenhuma violência para ser eficaz, é mais forte que a persuasão e a discussão"15.

Assim como o senhor governa a própria casa, o rei-filósofo deveria governar a cidade com essa autoridade racional, para conduzi-la ao mais próximo possível da ideia verdadeira de Cidade. A ausência de arbitrariedade dessa autoridade residia no fato de ela não ser uma obra humana, como é a vontade do tirano, mas por ser de origem transcendente, e somente o filósofo nela seria perito: “Aqui, o conceito de perito entra pela primeira vez na esfera da ação política, e o estadista é tido como competente para lidar com assuntos humanos no sentido em que o carpinteiro é competente para fazer mobílias ou o médico para curar o doente"16. Contudo, o problema é que tal autoridade era apenas assimilada por poucos, os filósofos, então como o povo a obedeceria voluntariamente, sem violência e persuasão? Com efeito, esse é um dos principais problemas do pensamento político de Platão, que para ser revolvido o próprio filósofo teve de desviar o foco da pura razão para o mito, uma vez que este meio seria o mais adequado para envolver o povo aos seus propósitos ${ }^{17}$.

Por meio do mito de recompensa e punição após a morte, no décimo livro d'A República, Platão quis resolver, sem violência e persuasão, o problema da obediência de um povo. Trata-se do "mito de Er", um homem que morreu em batalha e que, antes de seu enterro, ressuscitou e contou o que vira no mundo dos mortos. Quanto aos punidos, ele dizia: "cada alma recebia, para

\footnotetext{
${ }^{14}$ ARENDT, H. “Que é autoridade?". In: ARENDT, H. Entre o passado e o futuro. Tradução de Mauro W. Barbosa. Ed. São Paulo: Perspectiva, 2005, p. 153.

${ }^{15}$ ARENDT, H. “Que é autoridade?”. In: ARENDT, H. Entre o passado e o futuro. Tradução de Mauro W. Barbosa. Ed. São Paulo: Perspectiva, 2005, p. 147.

${ }^{16}$ ARENDT, H. “Que é autoridade?". In: ARENDT, H. Entre o passado e o futuro. Tradução de Mauro W. Barbosa. Ed. São Paulo: Perspectiva, 2005, p. 151.

${ }^{17}$ Platão tinha amplo conhecimento da função do mito para envolver a multidão dominada pelas paixões.
}

\begin{tabular}{|c|c|c|c|c|c|}
\hline intuitio & $\begin{array}{c}\text { ISSN } \\
1983-4012\end{array}$ & Porto Alegre & Vol.11- No .2 & $\begin{array}{c}\text { Dezembro } \\
2018\end{array}$ & p.101-122 \\
\hline
\end{tabular}


A Importância da Reflexão Arendtiana Acerca da Crise da Autoridade para uma Possível Interpretação Política da Sentença Nietzcheana "Deus Está Morto"

cada falta, dez vezes a sua punição e cada punição durava cem anos, ou seja, a duração da vida humana, a fim de que a expiação fosse o décuplo do crime"18; quanto aos recompensados: "os que, em vez disso, tinham praticado o bem à sua volta, tinham sido justos e piedosos, recebiam, na mesma proporção, a recompensa merecida"19. A ideia central é que quem agisse conforme o mal seria castigado na vida futura e quem agisse conforme o bem seria recompensado na mesma proporção. Não há aqui, portanto, nenhuma imposição por violência externa, pois Platão recorre ao discurso mítico e não à força; ademais, também não há persuasão, pois o filósofo espera que suas estórias sejam naturalizadas como a dos poetas, a saber, não em virtude de argumentos racionais, mas por fantasia, superstição e paixão.

Segundo a interpretação de Arendt, é evidente que Platão não acreditava em seus mitos, pois a punição e a recompensa contradiziam a sua doutrina da imortalidade da alma sem o corpo: "uma das indicações mais claras do caráter político desses mitos é, de fato, em flagrante contradição com sua doutrina da imortalidade do corpo, e essa contradição de modo algum escapou ao próprio Platão" 20 . No pensar do filósofo, o povo "não tem experiência alguma com verdade filosófica além do âmbito da percepção sensível e não podem, naturalmente, persuadir-se da imortalidade de uma alma sem o corpo" ${ }^{21}$. Visto isso, foi necessário que o castigo e a recompensa fossem pensados conforme a dor e o prazer corpóreo, para que a multidão obedecesse conforme a fuga do doloroso e a procura do prazeroso. Se a alma imortal é insensível, então Platão se contradiz com o seu mito, porém, sua contradição é justificada se é utilizada como um artifício político.

Ao construir o mito de punição e recompensa para os incapacitados de contemplar a beleza da verdade, Platão assim inaugura um novo ramo do saber, que ele denominou teologia. Foi o filósofo que cunhou essa palavra pela primeira vez, que neste contexto nada tem a ver com a interpretação do texto sagrado bíblico. Em verdade, a teologia "era para ele uma parte integrante da 'Ciência Política', especificamente aquela parte que ensinava aos poucos como governar sobre os muitos" 22 . No cerne desse saber, estava a ideia de Deus, como fundamento

\footnotetext{
${ }^{18}$ PLATÃO. A República. Tradução de Enrico Corvisieri. São Paulo: Abril Cultural, 1997, p. 346.

${ }^{19}$ PLATÃO. A República. Tradução de Enrico Corvisieri. São Paulo: Abril Cultural, 1997, p. 346.

${ }^{20}$ ARENDT, H. “Que é autoridade?". In: ARENDT, H. Entre o passado e o futuro. Tradução de Mauro W. Barbosa. Ed. São Paulo: Perspectiva, 2005, p. 174.

${ }^{21}$ ARENDT, H. “Que é autoridade?". In: ARENDT, H. Entre o passado e o futuro. Tradução de Mauro W. Barbosa. Ed. São Paulo: Perspectiva, 2005, p.172.

${ }^{22}$ ARENDT, H. “Que é autoridade?". In: ARENDT, H. Entre o passado e o futuro. Tradução de Mauro W. Barbosa. Ed. São Paulo: Perspectiva, 2005, p. 175.
}

\begin{tabular}{|c|c|c|c|c|c|}
\hline intuitio & $\begin{array}{c}\text { ISSN } \\
1983-4012\end{array}$ & Porto Alegre & Vol.11- No.2 & $\begin{array}{c}\text { Dezembro } \\
2018\end{array}$ & p.101-122 \\
\hline
\end{tabular}


A Importância da Reflexão Arendtiana Acerca da Crise da Autoridade para uma Possível Interpretação Política da Sentença Nietzcheana "Deus Está Morto"

seguro que julga as ações e mede as punições e recompensas em outra vida: "é um recurso político, 'medida das medidas', isto é o padrão pelo qual se podem fundar cidades e decretar regras de comportamento para a multidão" ${ }^{23}$. Deus surge com um caráter funcional, como um executor da justiça, cuja soberania deve se impor para ser obedecido.

Contudo, com a teologia política, a noção de autoridade de Platão não conseguiu se desvencilhar totalmente da violência e da persuasão. Ao que parece, seu mito de punição e recompensa sintetizou elementos das duas. Da persuasão - elemento central da política grega Platão retirou o poder dos argumentos; e da violência, retirou a obediência através do medo, que é a marca da tirania e da relação privada entre senhor e escravo, embora lhe subtraísse a força. Consequentemente, sua teologia conseguiu convencer não por argumentos racionais, mas pelo medo do castigo de Deus, exercendo uma espécie de tirania sem violência externa, mas interna e psicológica. Porém, de qualquer modo, esse foi o modelo de autoridade - muito mais que a romana - que o Ocidente herdou. Sem dúvida, os próprios romanos ao recepcionarem os textos gregos contribuíram para isso, pois "os grandes autores gregos tornaram-se autoridades nas mãos dos romanos e não dos gregos" 24 . Com efeito, mais tarde isso colaboraria com a própria derrota da tradição romana, uma vez que o platonismo nela estabelecido contribuiria, em virtude do mito de punição e recompensa em outro mundo, para a assimilação do cristianismo como nova religião do Império. Dessa forma, seria na hierarquia eclesiástica romana onde o modelo de autoridade platônico mais se realizaria: “é como se apenas na era cristã os invisíveis padrões de medida espirituais de Platão, pelos quais os assuntos visíveis e concretos dos homens deveriam ser medidos e julgados, se tivessem desdobrado em sua plena eficácia política" ${ }^{\text {}}$.

Mas não foi só o cristianismo via platonismo que modificou a autoridade romana, pois a própria tradição romana de se expandir continuamente se preservou na cultura cristã, tanto que esta se tornou uma religião de pretensões universais. Contudo, para Arendt, com a laicização do mundo decorrente da crise da autoridade e da tradição, essas pretensões universais não parecem mais trazer nenhum valor político. Em outras palavras, aquela teologia política iniciada por Platão e desenvolvida pela Igreja, baseada no mito de punição e recompensa em uma vida futura,

\footnotetext{
${ }^{23}$ ARENDT, H. “Que é autoridade?”. In: ARENDT, H. Entre o passado e o futuro. Tradução de Mauro W. Barbosa. Ed. São Paulo: Perspectiva, 2005, p. 175.

${ }^{24}$ ARENDT, H. “Que é autoridade?". In: ARENDT, H. Entre o passado e o futuro. Tradução de Mauro W. Barbosa. Ed. São Paulo: Perspectiva, 2005, p. 167.

${ }^{25}$ ARENDT, H. “Que é autoridade?". In: ARENDT, H. Entre o passado e o futuro. Tradução de Mauro W. Barbosa. Ed. São Paulo: Perspectiva, 2005, p. 170.
}

\begin{tabular}{|c|c|c|c|c|c|}
\hline intuitio & $\begin{array}{c}\text { ISSN } \\
1983-4012\end{array}$ & Porto Alegre & Vol.11- No.2 & $\begin{array}{c}\text { Dezembro } \\
2018\end{array}$ & p.101-122 \\
\hline
\end{tabular}


A Importância da Reflexão Arendtiana Acerca da Crise da Autoridade para uma Possível Interpretação Política da Sentença Nietzcheana "Deus Está Morto"

encontra o seu esgotamento no momento em que estas crenças perderam a sua função política. Nas palavras de Arendt:

\begin{abstract}
Superficialmente falando, a perda da crença em existências futuras é politicamente, senão espiritualmente, a distinção mais significativa entre o presente período e os séculos precedentes. E essa perda é definitiva. Não importando quão religioso o nosso mundo possa tornar a ser, ou quanta fé autêntica ainda exista nele, ou ainda quão profundamente nossos valores morais possam se enraizar nos nossos sistemas religiosos, o modo do inferno não está mais entre os motivos que impediriam ou estimulariam as ações da massa. Isso parece inevitável, desde que a autoridade do mundo envolve a separação das esferas religiosa e política da vida; sob tais circunstâncias, a religião estava fadada a perder seu elemento político, assim como a vida pública a perda sanção religiosa da autoridade transcendente. ${ }^{26}$
\end{abstract}

Embora a crença numa vida futura, como ideia central do culto religioso, mantenha a sua “autoridade" na esfera privada, ela já não pode ter pretensões políticas justamente porque carece de autoridade no sentido público-político. Desse modo, qualquer tentativa de provar o contrário pode ser desastrosa, resultando em fundamentalismo e violência. O Deus, enquanto artifício central da teologia política de Platão, já não obriga a multidão a mais nada, pois já não lhe impõe a psicologia do medo em conjunto. No próximo tópico, o presente artigo pretende alcançar o seu objetivo principal, inferindo, das conclusões arendtianas, a ideia de que a sentença nietzscheana sobre a morte de Deus se relaciona com a morte de sua autoridade política, uma vez que por um longo período de tempo esta foi sua razão de existir entre os povos.

\title{
4. O Significado Político da Sentença Nietzscheana "Deus está morto"
}

De acordo com o que foi exposto acerca da crise da autoridade, além da importância de Platão para a construção ocidental deste conceito, é possível uma aproximação entre Arendt e Nietzsche. Se a autoridade esteve alicerçada na tradição, então o filósofo tem algo a dizer a seu respeito, uma vez que este foi um dos seus principais problemas.

Pensa-se de que forma a reflexão de Arendt sobre a tradição pode auxiliar uma interpretação política da sentença nietzscheana "Deus está morto". De um modo geral, essa sentença não é pensada politicamente, mas limitada ao universo dos valores morais, no sentido de que a morte de Deus representa o fim do fundamento dos valores até então considerados

${ }^{26}$ ARENDT, H. "Que é autoridade?". In: ARENDT, H. Entre o passado e o futuro. Tradução de Mauro W. Barbosa. Ed. São Paulo: Perspectiva, 2005, p. 180.

\begin{tabular}{|c|c|c|c|c|c|}
\hline intuitio & $\begin{array}{c}\text { ISSN } \\
1983-4012\end{array}$ & Porto Alegre & Vol.11 $-\mathrm{N}^{\circ} .2$ & $\begin{array}{c}\text { Dezembro } \\
2018\end{array}$ & p.101-122 \\
\hline
\end{tabular}


A Importância da Reflexão Arendtiana Acerca da Crise da Autoridade para uma Possível Interpretação Política da Sentença Nietzcheana "Deus Está Morto"

superiores. Na obra nietzscheana, ela surgiu pela primeira vez no aforismo 125 d' A Gaia ciência, denominado $O$ homem louco:

\begin{abstract}
Não ouviram falar daquele homem louco que em plena manhã acendeu uma lanterna e correu ao mercado, e pôs-se a gritar incessantemente: "Procuro Deus! Procuro Deus!"? E como lá se encontrassem muitos daqueles que não criam em Deus, ele despertou com isso uma grande gargalhada. Então ele está perdido? perguntou um deles. Ele se perdeu como uma criança? disse um outro. Está se escondendo? Ele tem medo de nós? Embarcou num navio? Emigrou? - gritavam e riam uns aos outros. O homem louco se lançou para o meio deles e transpassou-os com seu olhar. "Para onde foi Deus?", gritou ele, "já lhes direi! Nós o matamos - vocês e eu. Somos todos seus assassinos! [...]". ${ }^{27}$.
\end{abstract}

Poder-se-ia interpretar esta passagem apenas sob o ponto de vista moral, considerando a morte de Deus como a desvalorização dos valores de bem e mal em seus aspectos transcendentes e eternos. Contudo, é um equívoco pensar a crítica nietzscheana da moral divorciada da política, pois ele a define como "moral de rebanho", fazendo alusão a Platão, que pensa n'O político a atividade do estadista como similar à do pastor de rebanho: "espontaneamente se revelaria a arte de pastorear homens, e assim poderíamos descobrir o homem político e real, colocando-o como condutor e entregando-lhe, como um direito, as rédeas do Estado por serem homens que possuem a ciência que lhes é necessária" 28 . Segundo o ateniense, assim como os homens comuns poderiam pastorar os animais de rebanho, também o filósofo, como o mais próximo do Deus legislador, poderia pastorar os homens conforme o conhecimento da Verdade. Com base nessa ideia, percebe-se que Platão também não pensa a política divorciada da moral, haja vista que somente a partir de preceitos morais advindos do Deus é que o estadista pode manter coeso o seu rebanho humano. Dessa forma, é possível pensar a morte de Deus da qual fala Nietzsche, bem como o niilismo dela consequente, não apenas no âmbito ético, mas também no político, que inclusive oferece um horizonte favorável para compreender o aforismo 125 d'A Gaia Ciência.

A política é uma esfera da vida que deve ser compreendida mediante valores. Em Nietzsche, a diferença entre tradição e moral é apenas nominal, pois o conceito se refere aos mesmos valores. Desse modo, se a política esteve fundada na tradição, então ela também esteve fundada nos valores morais. Ademais, se é verdade o que diz Arendt, que o conceito de

${ }^{27}$ NIETZSCHE, F. A gaia ciência. Tradução de Paulo César de Souza. 1ed. São Paulo: Companhia das Letras, 2012 b, p. 137.

${ }^{28}$ PLATÃO. "Político". Tradução de Jorge Paleikat e Jão Cruz Costa. In: PLATÃO. Diálogos: O banquete - Fédon - Sofista - Político. Tradutor. Ed. São Paulo: Abril Cultural, 1972, p. 219 (Coleção Os pensadores).

\begin{tabular}{|c|c|c|c|c|c|}
\hline intuitio & $\begin{array}{c}\text { ISSN } \\
1983-4012\end{array}$ & Porto Alegre & Vol.11 - No.2 & $\begin{array}{c}\text { Dezembro } \\
2018\end{array}$ & p.101-122 \\
\hline
\end{tabular}


A Importância da Reflexão Arendtiana Acerca da Crise da Autoridade para uma Possível Interpretação Política da Sentença Nietzcheana "Deus Está Morto"

autoridade que o Ocidente herdou é platônico, e que no seu cerne se encontra a autoridade de Deus como aquele que pune e recompensa enquanto artifício da teologia política, então é totalmente cabível inferir disso que a "morte de Deus" da qual fala Nietzsche é a morte do fundamento político da tradição. Observa-se o que diz Ansell-Pearson, em seu livro An introduction to Nietzsche as political thinker: "De acordo com Nietzsche, é necessário reconhecer que, na modernidade, a crença na autoridade incondicional e na verdade definitiva está desaparecendo. O que caracteriza a época moderna é a secularização da autoridade política" (tradução nossa) ${ }^{29}$.

Talvez uma reflexão política da sentença "Deus está morto" esteja bem mais próxima do seu melhor sentido, uma vez que ela explica satisfatoriamente como Deus pode estar realmente morto e ao mesmo tempo permanecer viva as igrejas e a crença em sua entidade no mundo moderno. Assim, quando Nietzsche diz que Deus está morto, ele não está dizendo que a ideia de Deus não será mais objeto de culto privado $^{30}$. De fato, no aforismo 472 de Humano demasiado humano, ele diz que a religião, ou seja, o que oferece peso à palavra de Deus, deve se tornar mesmo uma coisa privada: "então necessariamente aparecerá o recurso de tratar a religião como assunto privado e remetê-la à consciência e ao costume de cada indivíduo" 31 . Comentando essa ideia, Ansell-Pearson estaca "que em uma sociedade na qual o Estado não é tão livre para se beneficiar da religião, e onde a sociedade tolera o pluralismo de crença e práticas religiosas, a religião passa a ser meramente um assunto privado, deixado à consciência e costume de cada indivíduo" (tradução nossa) ${ }^{32}$. Sendo assim, a ideia de Deus morre porque sua autoridade política morre, sendo importante apenas para o indivíduo. Em outras palavras, não é mais uma ideia que possui vida, no sentido de garantir a unidade de um povo ou uma nação. Em suma, é uma ideia que, com sua autoridade arruinada pela ciência, não é mais capaz de unir um grande número pessoas para um fim político em comum. Nesse sentido, afirma Peter Sloterdijk:

\footnotetext{
29 "According to Nietzsche it is necessary to recognise that in the modern age belief in unconditional authority and definitive truth is disappearing. What characterises the modern age is the secularisation of political authority" (ANSELL-PEARSON, K. "Nietzsche on modern politics". In: An introduction to Nietzsche as political thinker: the perfect nihilist. New York: Cambridge University Press, 1994, p. 85).

${ }^{30}$ Até porque é possível que se cultue um Deus morto.

${ }^{31}$ NIETZSCHE, F. Humano demasiano humano I: um livro para espíritos livres. Tradução de Paulo César de Souza. São Paulo: Companhia das Letras, 2005, p. 228.

32 "That in a society where the state is no longer free to profit from religion, and where society tolerates pluralism in religious beliefs and practices, religion will become merely a private affair, left to the conscience and customs of each individual". (ANSELL-PEARSON, K. "Nietzsche on modern politics". In: An introduction to Nietzsche as political thinker: the perfect nihilist. New York: Cambridge University Press, 1994, p. 87)
}

\begin{tabular}{|c|c|l|l|c|c|}
\hline intuitio & $\begin{array}{c}\text { ISSN } \\
1983-4012\end{array}$ & Porto Alegre & Vol.11- No.2 & $\begin{array}{c}\text { Dezembro } \\
2018\end{array}$ & p.101-122 \\
\hline
\end{tabular}


A Importância da Reflexão Arendtiana Acerca da Crise da Autoridade para uma Possível Interpretação Política da Sentença Nietzcheana "Deus Está Morto"

Aqui deve-se interessar-nos somente seu sentido político secundário. É suficiente saber que epocalizações de sucesso são frases políticas porque reinterpretam o status das coisas no tempo. Numa cultura monoteísticamente condicionada, declarar que Deus está morto implica um abalo em todas as referências e o anúncio de uma nova forma de mundo. Com "Deus" apaga-se o princípio do pertencer-se de todas as pessoas na unidade de um espaço criado. ${ }^{33}$

Discorda-se de Sloterdijk, porém, apenas neste ponto: que o sentido político seja secundário. Discorda-se pelo seguinte motivo: pois à medida que Nietzsche pensa a morte Deus, ao mesmo tempo, ele visualiza aquilo que o homem moderno está pondo em seu lugar como substituto, a saber, o Estado, que é político ${ }^{34}$. Em Assim falou Zaratustra, Nietzsche denomina o Estado de o mais "novo ídolo": "Sim, também a vós ele percebe, ó vencedores do velho Deus! Ficastes cansados na luta, e agora vosso cansaço serve ao novo ídolo"35; e diz ainda: "Tudo dará a vós, desde que o adoreis, o novo ídolo: assim compra ele o brilho de vossa virtude e o olhar de vossos olhos altivos" 36 . No aforismo 472 de Humano demasiado humano, a apresentação dessa substituição se torna ainda mais explícita:

Tão logo isto sucede, a disposição dos homens ainda motivados religiosamente, que antes adoravam o Estado como algo semi- ou inteiramente sagrado, torna-se decididamente hostil ao Estado; eles ficam à espreita das medidas do governo, procuram obstruir, atravessar, inquietar o máximo que puderem, e com o ardor de sua oposição impelem o partido contrário, o anti-religioso, a um entusiasmo quase fanático pelo Estado; no que ainda concorre secretamente o fato de nesses círculos de ânimos, desde a separação da religião, sentirem um vazio e buscarem provisoriamente criar, com a dedicação ao Estado, um substituto, uma espécie de preenchimento. ${ }^{37}$

Com efeito, a ideia de Deus se tornou uma ideia morta e refém das necessidades modernas; deixou de ser soberana, competindo com outros ídolos, como o dinheiro, a produção, a

${ }^{33}$ SLOTERDIJK, P. No mesmo barco: ensaio sobre a hiperpolítica. Tradução de Claudia Cavalcanti. São Paulo: Estação Liberdade, 1999, p. 59.

${ }^{34}$ Com esta intepretação, não se quer dizer que está errada a interpretação mais recorrente, a qual diz ser a ciência moderna a substituta de Deus. Uma leitura não exclui a outra, pois ciência e Estado podem substituir Deus em esferas distintas da vida. Mas, a noção do Estado como substituto de Deus pressupõe todo um trabalho da ciência dedicado à destruição da visão de mundo sagrada. Vê-se, por exemplo, o que diz Hegel: "Tem a ciência, pelo seu lado, o mesmo elemento formal do Estado: o seu fim é o conhecimento da verdade e, mais precisamente, da verdade racional e objetiva" (HEGEL, G. H. F. Princípios da filosofia do direito. Tradução de Orlando Vitorino. São Paulo: Martins Fontes, 1997, p. 241).

${ }^{35}$ NIETZSCHE, Assim falou Zaratustra. Tradução de Paulo César de Souza. São Paulo: Companhia das Letras, 2011, p. 49.

${ }^{36}$ NIETZSCHE, Assim falou Zaratustra. Tradução de Paulo César de Souza. São Paulo: Companhia das Letras, 2011, p. 49.

${ }^{37}$ NIETZSCHE, F. Humano demasiano humano I: um livro para espíritos livres. Tradução de Paulo César de Souza. São Paulo: Companhia das Letras, 2005, p. 229.

\begin{tabular}{|c|c|c|c|c|c|}
\hline intuitio & $\begin{array}{c}\text { ISSN } \\
1983-4012\end{array}$ & Porto Alegre & Vol.11 - No.2 & $\begin{array}{c}\text { Dezembro } \\
2018\end{array}$ & p.101-122 \\
\hline
\end{tabular}


A Importância da Reflexão Arendtiana Acerca da Crise da Autoridade para uma Possível Interpretação Política da Sentença Nietzcheana "Deus Está Morto"

indústria e a tecnologia, pelo tempo do homem. No entanto, esse mesmo homem encontrou no Estado um substituto para gerenciar todas essas coisas, inclusive Deus. Já que Deus não funciona mais como esse elemento político de unificação da multidão, então se inventa o Estado como essa soberania que a une.

Animado pela ideia de sujeito, o homem confiou a si mesmo o fundamento da organização política, na qual ele é representado pelo Estado. Contudo, essa relação promete ser mais substancial do que mostra o seu fenômeno. Como observa Tamsin Shaw, "os Estados podem reforçar a sua autoridade por meio de um apelo aos pontos de vista filosóficos, os quais parecem fornecer-lhes alguma forma de justificativa. Em sua palestra de 1872, 'Sobre o Futuro das Nossas Instituições de Ensino', Nietzsche afirma que o hegelianismo oferece esse tipo de apoio" (tradução nossa) ${ }^{38}$. No $§ 258$ dos Princípios da Filosofia da Direito, Hegel diz que o Estado não deve ser confundido com a sociedade civil, pois tal confusão faz crer que ele deve ter por função apenas atender aos interesses do indivíduo, sua segurança e liberdade pessoal, o que deixa a este facultativo ser ou não ser seu membro. Ora, para Hegel, a relação do indivíduo com o Estado não deve ser facultativa, mas racional e necessária, pois somente no Estado o indivíduo consegue conquistar sua objetividade, liberdade, verdade e moralidade ${ }^{39}$. Sendo assim, a vontade do indivíduo e a vontade do Estado devem coincidir na racionalidade e na universalidade do real, como Hegel afirma no $\S 261$ : “O Estado como realidade moral, compenetração do substancial e do particular implica que as minhas obrigações para com a realidade substancial sejam também a existência de minha liberdade particular, o que quer dizer que nele direito e dever se encontram reunidos numa só e mesma relação" ${ }^{40}$. Por conseguinte, disso se conclui que o Estado não busca se legitimar por meio de nenhuma tradição, mas pretende impor sua "autoridade" a partir de si mesmo, enquanto produto necessário da racionalidade e da moralidade dos indivíduos humanos. Com a crise da autoridade baseada numa longa tradição, o Homem moderno impõe sua "autoridade" sobre o próprio homem, o que corrompe a própria natureza da autoridade, que é extra-humana.

\footnotetext{
38 "States might reinforce their authority through an appeal to philosophical views that seem to provide them with some form of justification. In his 1872 lectures "On the Future of Our Educational Institutions," Nietzsche claims that Hegelianism offers this kind of support" (SHAW, T. "The Predatory State". In: Nietzsche's Political Skepticism. New Jersey: Princeton University Press, 2007, p. 25).

${ }^{39}$ HEGEL, G. H. F. Princípios da filosofia do direito. Tradução de Orlando Vitorino. São Paulo: Martins Fontes, 1997, p. 217.

${ }^{40}$ HEGEL, G. H. F. Princípios da filosofia do direito. Tradução de Orlando Vitorino. São Paulo: Martins Fontes, 1997, p. 226-227.
}

\begin{tabular}{|c|c|c|c|c|c|}
\hline intuitio & $\begin{array}{c}\text { ISSN } \\
1983-4012\end{array}$ & Porto Alegre & Vol.11- No.2 & $\begin{array}{c}\text { Dezembro } \\
2018\end{array}$ & p.101-122 \\
\hline
\end{tabular}


A Importância da Reflexão Arendtiana Acerca da Crise da Autoridade para uma Possível Interpretação Política da Sentença Nietzcheana "Deus Está Morto"

Neste sentido, é possível compreender o motivo pelo qual no aforismo 125 d' A gaia ciência os homens, mesmo sem crença em Deus, não apresentavam o mesmo desespero do homem louco, ao contrário, riam-se uns aos outros daquele que não anunciava nenhuma novidade. No fundo, mesmo descrentes em Deus, tinham uma nova fé: "Transpôs-se a chegada do 'reino de Deus' para o futuro, para a Terra, para o elemento humano - mas se manteve no fundo a crença no antigo ideal" ${ }^{\prime 1}$. Aqueles ateus que estavam no mercado, portanto, não se preocupavam com a morte de Deus porque já tinham o Estado como seu mais novo ídolo; já o homem louco, notadamente uma alusão de Nietzsche a Diógenes, o cínico da antiguidade, sabia que não se podia nem mesmo acreditar no Estado, por isso sentia a morte de Deus com um fervor visionário, para além das falsas esperanças do ideal moderno.

Desta maneira, com a morte de Deus e da teologia política, o Estado moderno pretende ser seu substituto e assumir o papel de autoridade, embora sem uma tradição que o suporte, o que lhe trouxe fortes tendências "autoritárias", não no sentido romano, mas no sentido distorcido desta palavra, onde ela é confundida com tirania, ditadura e totalitarismo. Com alguma licença, poder-se-ia interpretar que o homem louco de Zaratustra já estava apontando para a onipresença do Estado nos regimes totalitários de uma forma incrivelmente antecipadora, onde a vontade de poder se apossa da vida sem uma autoridade que possa protegê-la da violência.

De acordo com Nietzsche, Estado absoluto sem religião é um grande equívoco e não consegue manter-se por muito tempo: “enquanto o Estado ou, mais precisamente, o governo dele considerar se a religião deve ser mantida ou eliminada, muito provavelmente se decidirá pela conservação da religião" 42 . Isso porque, em toda tradição, o Estado sempre precisou da religião e de sua autoridade para se legitimar. Segundo Ansell-Pearson, "a religião é útil porque, por meio do cultivo do sentimento popular e da identidade comum, assegura a paz civil interna e estimula o desenvolvimento contínuo de uma cultura" (tradução nossa ${ }^{43}$. Logo, sem estar assim legitimado pela religião, é impossível que a vontade do Estado coincida com a vontade do indivíduo. A razão disso se deve ao que Nietzsche diz no seu fragmento póstumo: “O 'Estado' não é íntimo o

\footnotetext{
${ }^{41}$ NIETZSCHE, F. Fragmentos póstumos: 1887-1889: volume VII. Tradução de Marco Antônio Casanova. Rio de Janeiro: Forense Universitária, 2012b, p. 78.

42 NIETZSCHE, F. Humano demasiano humano I: um livro para espíritos livres. Tradução de Paulo César de Souza. São Paulo: Companhia das Letras, 2005, p. 227.

43 "Religion is useful in that, through the cultivation of popular sentiment and a common identity, it secures internal civil peace and fosters the continuous development of a culture" (ANSELL-PEARSON, K. "Nietzsche on modern politics". In: An introduction to Nietzsche as political thinker: the perfect nihilist. New York: Cambridge University Press, 1994, p. 86).
}

\begin{tabular}{|c|c|c|c|c|c|}
\hline intuitio & $\begin{array}{c}\text { ISSN } \\
1983-4012\end{array}$ & Porto Alegre & Vol.11 $-\mathrm{N}^{\circ} .2$ & $\begin{array}{c}\text { Dezembro } \\
2018\end{array}$ & p.101-122 \\
\hline
\end{tabular}


A Importância da Reflexão Arendtiana Acerca da Crise da Autoridade para uma Possível Interpretação Política da Sentença Nietzcheana "Deus Está Morto"

suficiente, secreto o suficiente, a 'condução da consciência moral' lhe escapa"44. Ora, é justamente isso que a disposição que concebe Estado como "novo ídolo” quer superar, para tornálo racionalmente íntimo e uma necessidade moral. Com a morte de Deus, o Estado se separa da religião, mas não da atitude religiosa, que passa a ser com relação a si mesmo. Porém, isso tem o seu preço, pois como se torna outra religião, ele também há de ser afetado pela morte Deus, porque também morre tudo o que procura substituir a antiga autoridade: “desaparecer a religião, o Estado inevitavelmente perderá seu antigo véu de Ísis e não mais despertará reverência»45. Desse modo, surge "a suspeita em relação a todos os que governam, a percepção do que há de inútil e desgastante nessas lutas de pouco fôlego tem de levar os homens a uma decisão totalmente nova"46. O que há de ser esta nova situação? Trata-se da supressão do Estado e a predominância da esfera privada e do indivíduo, caminho que Nietzsche diz ser o da democracia moderna: "a democracia moderna é a forma histórica do declínio do Estado" ${ }^{27}$.

Assim, somente após a barbárie do substituto político de Deus, o Estado totalitário, é que a morte desse artifício político se torna mais compreensível e observável em uma realidade política ainda incompreendida, uma realidade com traços nietzscheanos, que muitos dizem ser pós-moderna:

Pós-modernidade é a época do "depois de Deus", e do pós-impérios clássicos com suas aberturas mundiais locais. [...] Código teológico a parte, assim falou Nietzsche sobre que inspira nosso tempo com esperança e horror; alguma coisa está morta e só pode desmoronar mais rápida ou lentamente, mas de alguma forma avançam a vida e a civilização e se cristalizam em novidade não compreendidas. Entre esse "alguma coisa" e esse "de alguma forma" reside aquilo que dá o que pensar na terceira era mundial. ${ }^{48}$

Nesse estado de coisa, “o Estado se torna um castelo de areia, o absenteísmo se infiltra em todas as estruturas aparentemente sólidas, os ligamento sociais se estendem no vazio"49. Para

\footnotetext{
${ }^{44}$ NIETZSCHE, F. Fragmentos póstumos: 1887-1889: volume VII. Tradução de Marco Antônio Casanova. Rio de Janeiro: Forense Universitária, 2012b, p. 540.

${ }^{45}$ NIETZSCHE, F. Humano demasiano humano I: um livro para espíritos livres. Tradução de Paulo César de Souza. São Paulo: Companhia das Letras, 2005, p. 230.

${ }^{46}$ NIETZSCHE, F. Humano demasiano humano I: um livro para espíritos livres. Tradução de Paulo César de Souza. São Paulo: Companhia das Letras, 2005, p. 230.

${ }^{47}$ NIETZSCHE, F. Humano demasiano humano I: um livro para espíritos livres. Tradução de Paulo César de Souza. São Paulo: Companhia das Letras, 2005, p. 230.

${ }^{48}$ SLOTERDIJK, P. No mesmo barco: ensaio sobre a hiperpolítica. Tradução de Claudia Cavalcanti. São Paulo: Estação Liberdade, 1999, p. 59-60.

${ }^{49}$ SLOTERDIJK, P. No mesmo barco: ensaio sobre a hiperpolítica. Tradução de Claudia Cavalcanti. São Paulo: Estação Liberdade, 1999, p. 69.
}

\begin{tabular}{|c|c|l|l|c|c|}
\hline intuitio & $\begin{array}{c}\text { ISSN } \\
1983-4012\end{array}$ & Porto Alegre & Vol.11- No.2 & $\begin{array}{c}\text { Dezembro } \\
2018\end{array}$ & p.101-122 \\
\hline
\end{tabular}


A Importância da Reflexão Arendtiana Acerca da Crise da Autoridade para uma Possível Interpretação Política da Sentença Nietzcheana "Deus Está Morto"

Sloterdijk, a "morte de Deus" vista sob um ponto de vista político representa o mundo pósmoderno, caracterizado pela pluralidade, pelo perspectivismo, pela descentralização e desoneração da sociedade industrial globalizada, que marca o fim da política clássica baseada na autoridade, que teve na figura do Estado o seu último suspiro: "enquanto a política, no entendimento clássico, significou a arte do pertencer-se em cidades da era agrária e grandes impérios, para ela chegou o momento crítico com a "morte de Deus" "50. Para Sloterdijk, a política clássica, de uma maneira metafórica, seria como reparar os danos do mito da torre de Babel, pois ela começa a ver a pluralidade de linguagens culturais como uma catástrofe política, uma vez que quanto maior é o corpo político e mais diversificado a suas partes mais difícil é exercer sobre ele alguma espécie de autoridade ${ }^{51}$. Como ele coloca, a grande dificuldade da política clássica foi saber como exercer autoridade sob o ponto de vista demográfico mesmo:

Como mil, dez mil, cem mil hordas - no formato de "grandes famílias" entre 30 a 100 membros - podem reunir-se de tal forma que se lhes possa exigir esforços em prol de uma obra comum, algo como contribuições para as instalações de irrigação, cruzadas e impostos de reunificação? Como podem "falar" a tão grandes números de pessoas e convencê-las a se sentirem participantes daquilo que é "grande" - até chegar à disposição de ir ao encontro da morte em exércitos de milhões de outras forças de igual ordem de grandeza, a fim de assegurar aos "próprios" sucessores aquilo que os ideólogos chamam de futuro? $?^{52}$

Com isso, a crise a autoridade da política clássica na sociedade industrial não parece se dever apenas a fatores ideológicos, pois é o próprio volume gigantesco da multidão que também impossibilita a sua reunião em um Grande organizado politicamente. A teologia política de Platão, procedimento que ensina poucos a governar muitos, teria falhado porque os muitos vieram a suprimir os poucos em massa. Precisamente isso é a morte de Deus, e o homem louco do aforismo 125 d'A Gaia Ciência estaria certo em dizer que não foi nem este nem aquele que matou Deus, mas nós que o matamos, um “nós” que, de tão numeroso, já não consegue ter uma imagem total de si mesmo como um "nós". Contudo, algo começa a se mostrar depois do fracasso dessas tentativas totalitárias de substituir o Deus após a sua morte: o pluralismo pós-

\footnotetext{
${ }^{50}$ SLOTERDIJK, P. No mesmo barco: ensaio sobre a hiperpolítica. Tradução de Claudia Cavalcanti. São Paulo: Estação Liberdade, 1999, p. 60.

${ }^{51}$ SLOTERDIJK, P. No mesmo barco: ensaio sobre a hiperpolítica. Tradução de Claudia Cavalcanti. São Paulo: Estação Liberdade, 1999, p. 12.

${ }^{52}$ SLOTERDIJK, P. No mesmo barco: ensaio sobre a hiperpolítica. Tradução de Claudia Cavalcanti. São Paulo: Estação Liberdade, 1999, p. 31.
}

\begin{tabular}{|c|c|c|c|c|c|}
\hline intuitio & $\begin{array}{c}\text { ISSN } \\
1983-4012\end{array}$ & Porto Alegre & Vol.11 $-\mathrm{N}^{\circ} .2$ & $\begin{array}{c}\text { Dezembro } \\
2018\end{array}$ & p.101-122 \\
\hline
\end{tabular}


A Importância da Reflexão Arendtiana Acerca da Crise da Autoridade para uma Possível Interpretação Política da Sentença Nietzcheana "Deus Está Morto"

moderno. Com efeito, é esperado que um Grande, sem uma autoridade que o sustente, precipitese e se fragmente em partes independentes, talvez formando uma sociedade baseada em tribos.

\section{Considerações Finais}

Demonstrou-se como a reflexão arendtiana sobre a crise e o fim da autoridade no mundo ocidental pôde contribuir satisfatoriamente para uma leitura política da sentença nietzscheana "Deus está morto". Para Arendt, o conceito de autoridade que o Ocidente herdou é de origem platônica. Ele nasceu da denominada teologia política de Platão, que consistia em ensinar procedimentos que permitiam a muitos governarem poucos, por meio do mito de punição e recompensa numa vida futura, onde Deus é o juiz supremo. Assim, tomando isso como ponto de partida da inferência, considerou-se a sentença de Nietzsche "Deus está morto" sob um ponto de vista político, interpretando-a como uma fórmula para o fim do fundamento da política clássica de rebanho, iniciada com Platão em seu diálogo $O$ político e desenvolvida pelo cristianismo.

Além disso, analisou-se como a interpretação política da sentença de Nietzsche não é arbitrária, uma vez que o próprio filósofo, ao procurar o substituto para Deus na modernidade, identificou-o no Estado, que é uma categoria exclusivamente política. Desse modo, o Estado surge como a tentativa moderna e secular de manter viva a pretensão da política clássica, onde uma quantidade considerável de pessoas pode ser governada, formando um Grande organizado. Contudo, esse mesmo Estado, ao se pretender o novo Deus e sem nenhuma tradição que lhe desse semelhante autoridade, tornou-se totalitário e violento.

Para Sloterdijk, filósofo alemão e intérprete de Nietzsche, o significado político da morte de Deus veio a se tornar mais compreensível após o fracasso dos regimes totalitários. Assim, já não é possível pensar em nenhum conceito que possa unir a grande multidão em seu torno, nem Deus nem seu substituto Estado. Sem uma autoridade unificadora, o mundo agora se fragmenta em um pluralismo que muitos dizem ser o caráter da vida pós-moderna. Portanto, uma das chaves para se compreender essa pluralidade consiste nisto que foi o problema da presente investigação: o significado político da morte de Deus.

\section{Referências}

ANSELL-PEARSON, K. "Nietzsche on modern politics". In: An introduction to Nietzsche as political thinker: the perfect nihilist. New York: Cambridge University Press, 1994, p. 83-97.

ARENDT, H. "Que é autoridade?". In: ARENDT, H. Entre o passado e o futuro. Tradução de Mauro W. Barbosa. Ed. São Paulo: Perspectiva, 2005, p. 127-187.

\begin{tabular}{|c|c|l|l|c|c|}
\hline intuitio & $\begin{array}{c}\text { ISSN } \\
1983-4012\end{array}$ & Porto Alegre & Vol.11- No.2 & $\begin{array}{c}\text { Dezembro } \\
2018\end{array}$ & p.101-122 \\
\hline
\end{tabular}


A Importância da Reflexão Arendtiana Acerca da Crise da Autoridade para uma Possível Interpretação Política da Sentença Nietzcheana "Deus Está Morto"

HEGEL, G. H. F. Princípios da filosofia do direito. Tradução de Orlando Vitorino. São Paulo: Martins Fontes, 1997. NIETZSCHE, F. Humano demasiano humano I: um livro para espíritos livres. Tradução de Paulo César de Souza. São Paulo: Companhia das Letras, 2005.

. Assim falou Zaratustra. Tradução de Paulo César de Souza. São Paulo: Companhia das Letras, 2011. . A gaia ciência. Tradução de Paulo César de Souza. 1ed. São Paulo: Companhia das Letras, 2012a.

. Fragmentos póstumos: 1887-1889: volume VII. Tradução de Marco Antônio Casanova. Rio de Janeiro: Forense Universitária, 2012b.

PLATÃO. "Político". Tradução de Jorge Paleikat e Jão Cruz Costa. In: PLATÃo. Diálogos: O banquete - Fédon Sofista - Político. Tradutor. Ed. São Paulo: Abril Cultural, 1972, p. 206-269 (Coleção Os pensadores).

. A República. Tradução de Enrico Corvisieri. São Paulo: Abril Cultural, 1997.

SHAW, T. "The Predatory State". In: Nietzsche's Political Skepticism. New Jersey: Princeton University Press, 2007, p. 12-35.

SLOTERDIJK, P. No mesmo barco: ensaio sobre a hiperpolítica. Tradução de Claudia Cavalcanti. São Paulo: Estação Liberdade, 1999.

\begin{tabular}{|c|c|c|c|c|c|}
\hline intuitio & $\begin{array}{c}\text { ISSN } \\
1983-4012\end{array}$ & Porto Alegre & Vol.11- No.2 & $\begin{array}{c}\text { Dezembro } \\
2018\end{array}$ & p.101-122 \\
\hline
\end{tabular}

